\title{
Heidegger e a Doutrina da Personalidade em Kant
}

\author{
Jean Leison Simão \\ Mestrando em Filosofia pela Universidade Federal \\ de Santa Maria (UFSM)
}

Resumo: Trata-se do desenvolvimento do conceito de personalidade em Kant, segundo Heidegger, sob três determinações: personalidade transcendental, personalidade psicológica e personalidademoral.Especificamente, o objetivo é definir o conceito estrito e autêntico de personalidade - expresso na personalidade moral - em relação aos conceitos mais gerais, tanto da personalidade transcendental quanto da psicológica. Nos conceitos mais gerais uma ontologia não é possível. $\mathrm{Na}$ determinação da personalidade transcendental não se manifesta o ente do sujeito, portanto, não podemos revelar o ser deste ente; já na determinação da personalidade psicológica o ente do sujeito é manifestado, entretanto o que inviabiliza a ontologia é o fato de este ente (a alma) não poder ser tomado em si mesmo, isto é, não poder ser independente do corpo. $\mathrm{O}$ conceito mais estrito e autêntico em Kant, segundo Heidegger, é o que torna possível uma ontologia, na medida em que é o único que, a partir da peculiaridade da autoconsciência moral em relação à autoconsciência empírica e a transcendental, manifesta onticamente e de imediato a pessoa naquilo que é: em sua dignidade.

Palavras-chave: personalidade transcendental, personalidade psicológica, personalidade moral, Kant, Heidegger.
Abstract: It is about the development of the concept of personality in Kant according to Heidegger and under three determinations: transcendental personality, psychological personality and moral personality. Specifically, the objective is to define the strict and authentic concept of personality - expressed in the moral personality - related to the most general concepts, not only of the transcendental personality but also of the psychological one. In the most general concepts the ontology is not possible. In determining the transcendental personality the subject entity is not manifested. However, what makes the ontology not feasible is the fact that this entity (the soul) is not taken in itself, that is, it is not independent from the body. The most strict and authentic concept in Kant according to Heidegger is what makes possible one ontology once it is the only one to, from the peculiarity of the moral auto-consciousness compared to the empirical auto-consciousness, manifest ontologically and promptly the person in what he is: his dignity.

Keywords: transcendental personality, psychological personality, moral personality, Kant, Heidegger. 


\section{Introdução}

No terceiro capítulo da obra Os problemas fundamentais da fenomenologia, Heidegger trata, em três seções (13, 14 e 15), da tese ontológica moderna sobre os modos básicos do ser da natureza (res extensa) e do espírito (res cogitans). Para sermos mais precisos: na seção 13, Heidegger se propõe a caracterizar tal distinção a partir da concepção kantiana do problema, com o objetivo de mostrar que os filósofos da modernidade - os quais pretendiam se orientar fundamentalmente para o sujeito - não cumprem com sua promessa, pois os problemas de princípio subjacentes na orientação ontológica moderna permanecem dependentes da ontologia tradicional (antiga e medieval). Esses problemas de princípio serão propriamente tema da seção 14, que se constitui de uma análise crítica da concepção de personalidade em Kant - cuja interpretação do ser se desenvolve vinculada ao conceito de subsistência -, o que conduz à necessidade de colocação de uma questão mais fundamental que interroga pelo ser. Por conseguinte, é na seção 15 que Heidegger conclui abordando a problemática fundamental da determinação do ser do "sujeito" (Dasein), não sob uma orientação unilateralmente subjetivista, como fizeram os modernos, senão como ponto de partida da problemática filosófica.

No presente artigo não nos ocuparemos da reconstrução argumentativa heideggeriana das duas últimas seções. Limitaremonos apenas à primeira, mas não com o objetivo meramente de reconstruir a tematização da distinção ontológica dos modos do ser segundo a concepção de Kant. Nosso propósito é, sobretudo, o de investigar a caracterização heideggeriana da personalidade em Kant sob três determinações fundamentais: personalidade transcendental, personalidade psicológica e personalidade moral.

De certa forma, a proposta da seção 13 (a caracterização da distinção entre res cogitans e res extensa e a exposição dos princípios de tal distinção) pode ser identificada em nosso trabalho. Assim, encontramos nessa tematização da doutrina da personalidade em Kant um eu em geral, que é somente sujeito (o eu transcendental), e o eu que é sujeito num sentido estrito (o eu moral), portanto, a existência de ambos é dependente de nossa vontade, são fins, são 
res cogitans. Por outro lado, o eu psicológico é o eu em geral que é somente objeto, unido ao corpo (matéria), portanto, sua existência não é dependente de nossa vontade, é um meio, é uma res extensa. ${ }^{1}$ Não obstante, a definição de personalidade em sentido amplo, tanto da personalidade transcendental quanto da personalidade psicológica, não toca o sentido mais central e autêntico de pessoa, que se exprime na personalidade moral. O caráter mais central e autêntico dessa personalidade, em relação aos outros conceitos mais gerais, é o que, especificamente, pretendemos desenvolver.

\section{Os conceitos mais gerais de personalidade: personalidade transcendental e personalidade psicológica}

No final da seção 14 Heidegger afirma:

a subjetividade do sujeito é sinônimo de autoconsciência. Esta última constitui a efetividade, o ser deste ente. Daqui decorre que, numa compreensão radical do pensamento de Kant ou Descartes, o idealismo alemão (Fichte, Schelling, Hegel) visse a autêntica efetividade do sujeito na autoconsciência. ${ }^{2}$

Em Kant, de acordo com Heidegger, não podemos conhecer o ser do sujeito, no sentido de coisa em si mesma, isto é, como uma substância finita produzida por um ente originário, o ens infinitum (Deus), o único que, por ser aquele que produz, tem acesso ao ser do ente assim produzido. Nós, enquanto pessoas, enquanto entes finitos, somente podemos conhecer os efeitos das substâncias finitas, sejam elas pessoas (res cogitans) ou coisas (res extensa). Por conseguinte, não podemos conhecer o ser do sujeito, ele mesmo, na autoconsciência, senão apenas os efeitos, as suas determinações.

1. De acordo com a interpretação de Heidegger "segundo Kant, ambas, tanto a pessoa como a coisa [Sache], são res, coisas [Dinge] no mais amplo sentido, coisas que têm existência, que existem”. Heidegger, M. Los problemas fundamentales de la fenomenología. Trad. de Juan José Garcia Norro. Madri: Editorial Trotta, 2000, p. 197.

2. Idem, p. 216. (A numeração das páginas é referente ao original em alemão. $\mathrm{Na}$ tradução espanhola essa numeração aparece ao lado do corpo do texto). 
Isso vale sobretudo para a autoconsciência pura da personalidade transcendental e para a autoconsciência empírica da personalidade psicológica. Entretanto, no caso da autoconsciência moral da personalidade moral ocorre algo distinto, conforme a análise de Heidegger, como veremos. Não obstante, poderíamos perguntar como estão unificadas essas três determinações de personalidade em Kant. Pergunta legítima que mereceria uma resposta adequada se, segundo Heidegger, Kant se ocupasse da investigação dessa unificação, o que, na realidade, não ocorreu.

Deixando a problemática da unificação de lado, é certo que o sujeito existente (no sentido de subsistência ${ }^{3}$ ) tem três modos de determinação: ele existe como sujeito determinante (personalidade transcendental), como sujeito determinável (personalidade psicológica) e como sujeito que determina a si mesmo a partir de sua ação moral (personalidade moral).

Para Heidegger, encontramos o conceito formal de personalidade, no sentido de autoconsciência, no conceito de personalidade transcendental. Isso acontece porque o termo transcendental, em Kant, não deve ser compreendido (como propõem os neokantianos) sob o ponto de vista epistemológico. Transcendental na doutrina de Kant significa ontológico. Segundo Heidegger, "o conhecimento transcendental [em Kant] não se refere a objetos, isto é, ao ente, senão aos conceitos que determinam o ser do ente". ${ }^{4}$ O sistema desses conceitos faz parte de uma filosofia transcendental que é sinônimo de ontologia e não de epistemologia.

Doravante, de que maneira podemos conhecer a determinação da personalidade transcendental? Segundo Heidegger, a determinação do eu transcendental em Kant é fundamentalmente cartesiana. $\mathrm{O}$ eu, nesse sentido, é uma res cogitans, uma res que tem representações, isto é, que tem comportamentos específicos, as cogitationes (julgar, odiar, negar, perceber etc.). Cada uma das

3. Heidegger afirma que "Kant fala acerca do existir [Existieren] do homem e acerca da existência [Dasein] das coisas como fins; mas os termos Existieren e Dasein, para ele significam somente subsistência”. Idem, pp. 199-200.

4. Idem, p. 180. 
cogitationes é sempre acompanhada de um "eu penso" co-representado, mesmo que não seja propriamente pensado, pois, "segundo Descartes, cogitare é sempre cogito me cogitare". ${ }^{5}$

Entretanto, para Heidegger, Kant aceita a determinação cartesiana do ego, mas a concebe de uma maneira mais fundamental no tocante à ontologia. $\mathrm{O}$ sentido das determinações do eu, isto é, de suas representações, é o de representatio. O próprio termo "determinação" em Kant, segundo Heidegger, conserva o sentido de determinatio ou realitas, o que, na ontologia tradicional, remete aos predicados das coisas. Além disso, Heidegger afirma que se deve entender o conceito de "res" de modo ontologicamente mais rigoroso, a saber, como algo. Por conseguinte, o eu kantiano é um algo que tem predicados (as cogitaciones), um eu no sentido lógicogramatical. O eu é, mais precisamente, um subjectum - no sentido de categoria apofântica formal -, pois, como afirma Heidegger, “apofântica' é aquela categoria que pertence à estrutura do que é a estrutura formal do conteúdo enunciativo de uma proposição enunciativa em geral". ${ }^{6}$ Há, portanto, uma dependência íntima, sob o ponto de vista ontológico, entre o conceito de sujeito e o

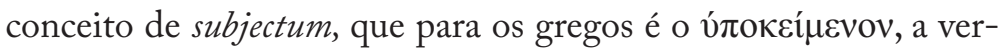
dadeira substância. ${ }^{7}$

Não obstante, ter predicados significa dizer que o eu transcendental, na acepção kantiana, seguindo a argumentação de Heidegger, tem consciência deles de forma peculiar. O sujeito é distinto de seus objetos (dos predicados) e, ao mesmo tempo, os tem, os conhece, ou seja, é um sujeito de predicados (objetos) e para objetos. A autoconsciência, em conseqüência, também é peculiar. Heidegger afirma que "em razão dessa peculiar forma de ter predicados, o sujeito é um sujeito peculiar, isto é, o eu é o sujeito

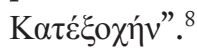
5. Idem, p. 177.
6. Idem, p.178.
7. Idem, ibidem.
8. Idem, ibidem. 
Este sujeito kantiano, ele mesmo, afirma Heidegger, não é um sujeito determinado, ou seja, não pode ser representado. Sobre esse sujeito não podemos dizer nada mais senão que ele é algo, mas não algo universal, anônimo, um eu lógico resultado de uma abstração lógica - como interpretam os neokantianos -, senão que é algo indeterminado, no sentido de que o seu ser é problemático. O eu lógico não é, segundo Heidegger, e como pretende Rickert, um eu pensado logicamente, senão que o eu "precisamente por sua essência é, em cada caso, meu". ${ }^{9}$ O eu lógico, em Kant, deve ser interpretado, segundo Heidegger, como o sujeito do logos, no sentido de um sujeito que subjaz em todo pensar.

Ora, se, como expusemos mais acima, a efetividade do sujeito se dá em sua autoconsciência, então como poderíamos sustentar uma autoconsciência de um sujeito que em si mesmo é indeterminado (isto é, não efetivo)? Não estaríamos diante de um evidente contra-senso?

Essas questões nos levam a investigar com mais detalhe em que consiste a autoconsciência do eu transcendental. De acordo com Heidegger, a autoconsciência é pura e se dá na forma de uma apercepção transcendental. Vejamos o que ele diz sobre isso:

Kant interpreta o eu como "unidade sintética original da apercepção [Apperzeption]". O que significa isso? O eu é o fundamento originário da unidade da multiplicidade de suas determinações no sentido de que, enquanto eu, eu as tenho todas juntas em relação comigo mesmo, as mantenho juntas, as uno, sintetizo. $O$ fundamento originário da unidade é o que é, é este fundamento como unificante, como sintético. A união da multiplicidade das representações e daquilo que é representado nelas tem sempre de ser pensado junto a elas. A união é de tal sorte que, ao pensar, eu também me penso a mim mesmo, ou seja, não apreendo simplesmente o pensado e o representado, não só o percebido, senão que em todo pensamento me penso a mim mesmo com ele. Não percebo o eu, senão que o apercebo. A unidade sintética original da apercep̧̧ão é a característica ontológica do sujeito assinalado. ${ }^{10}$

9. Idem, p. 194 (grifo nosso).

10. Idem, pp. 179-180. 
Portanto, somente podemos conhecer a determinação deste eu como um algo que unifica. Essa é, como Heidegger põe em relevo, a característica ontológica do sujeito transcendental. $\mathrm{O}$ eu é "a condição ontológica fundamental de todo ser"11 e não pertence às condições particulares de possibilidade que são os conceitos radicas do entendimento - as categorias -, mas é o que (enquanto fundamento) torna essas categorias possíveis. Mas o que é em si mesmo esse eu? Posto que seja a condição ontológica de todo pensar, não podemos dizer nada mais do que ser ele problemático, indeterminado.

O eu puro nunca se me dá como determinável para a determinação, isto é, para aplicar-lhe as categorias. É por esta razão que é impossível um conhecimento ôntico do eu e, por conseguinte, uma determinação ontológica dele. A única coisa que se pode dizer é que o eu é um "eu atuo". ${ }^{12}$

Para sustentar essa sua afirmação Heidegger cita Kant:

O "eu penso" expressa o ato de determinar minha existência [isto é, minha subsistência]. Por conseguinte, a existência está já dada mediante ele. Mas o modo segundo o qual devo determiná-la, isto é, pôr em mim a variedade que a ela lhe pertence, não se encontra, todavia, determinado através deste ato. Para isso [o dar-me a mim mesmo] se requer uma intuição, a qual se baseia numa forma dada a priori, a saber, o tempo, que é sensível e pertence à receptividade do determinável. Como não possuo outra intuição de mim mesmo que me subministra o determinante, do qual só tenho consciência de sua espontaneidade, antes do ato de determinar, à maneira como o tempo subministra o determinável, não posso determinar minha existência de um ser ativo por si mesmo, senão me represento somente a espontaneidade de meu pensar, isto é, do determinar. Minha existência segue sendo sempre determinável só de modo sensível, isto é, determinável enquanto existência de um fenômeno.

11. Idem, p. 181.

12. Idem, p. 205. 
Não obstante, é essa espontaneidade a que faz que me denomine inteligência. ${ }^{13}$

Portanto, não se pode afirmar que o "eu penso" pode ter consciência de si no momento em que manifesta a sua ação, pois o próprio atuar - uma vez que é mediado pela intuição - é um ato que, quando se apresenta, já está determinado. O "eu penso" tem consciência de si apenas enquanto determinante e não pode ser determinável pela receptividade, isto é, a partir das condições $a$ priori da intuição. Ele somente pode se representar como pura espontaneidade do determinar, antes mesmo de efetuar uma determinação. Por conseguinte, somente temos consciência do eu transcendental, isto é, de sua efetividade, como determinante, entretanto, não podemos saber o que é esse eu, uma vez que não podemos ter conhecimento ôntico do eu e determiná-lo em seu ser.

Com isso, a personalidade transcendental, enquanto revela um eu como fundamento ontológico de todo pensar, é a estrutura formal da personalidade. Isto é, na multiplicidade dos atos de pensamento temos consciência do eu, enquanto o mesmo que une esta e aquela representação. O eu é, portanto, a unidade que torna possível a multiplicidade. Esta é a estrutura formal da personalidade.

$\mathrm{Na}$ personalidade psicológica o eu não tem caráter ontológico, isto é, como um mesmo que torna possível a multiplicidade, mas antes se manifesta como um mesmo na multiplicidade. Assim sendo, não é o sujeito determinante (da espontaneidade), mas o sujeito determinável (da receptividade). A eu-idade na personalidade psicológica revela um eu que não é sujeito do pensamento apercebido, senão um eu que está no tempo e no espaço, um eu experimentado, um eu empírico, que, segundo Heidegger, coincide com o conceito de alma pensada como ideia. Portanto, o fundamento desse eu não é um fundamento ontológico, apesar de ser o eu puro a condição fundamental para a autoconsciência do eu empírico. $\mathrm{O}$ fundamento da alma é "como diz Kant, do ser animado, da vida em geral". ${ }^{14}$ A consciência de si do eu fático revela um eu subsistente

13. Idem, pp. 205-6.

14. Idem, p. 183.

48 
na experiência, enquanto um eu que é consciente de seus estados empíricos. Essa autoconsciência empírica é uma apreensão, que, segundo Heidegger, significa "percepção, experiência do subsistente, experiência dos processos psíquicos subsistentes mediante o denominado sentido interno". ${ }^{15}$ Mais adiante Heidegger cita Kant acrescentando que o homem tem autoconsciência não somente como alma, mas como alma unida a um corpo que é objeto dos sentidos externos.

Para a inteligência humana, a psicologia não é nada mais, nem pode tampouco ser nada mais, que a antropologia, isto é, conhecimento do homem, mas limitado à condição de que seja conhecido como objeto de sentido interno. Mas tem assim mesmo consciência de si como objeto dos sentidos externos, ou seja, tem um corpo, unido ao objeto de sentido interno que se chama alma do homem. ${ }^{16}$

Disso podemos concluir que na multiplicidade do aparecer, seja da alma, seja da alma unida ao corpo, o eu tem consciência de si como o mesmo em meio a seus estados empíricos que modificam continuamente. $\mathrm{O}$ eu apreendido é um eu que é somente objeto, é uma coisa [sache], e por isso se distingue do eu transcendental, o eu que subjaz no logos, que é somente sujeito. Não obstante, segundo Heidegger, a eu-idade do eu lógico "é a mesma em todos os sujeitos fáticos" ${ }^{17}$, ou seja, o eu determinante da apercepção é idêntico ao eu determinável; entretanto o eu determinável depende necessariamente do eu determinante. A consciência de si pode manifestar o eu como determinante (o que pensa e intui) ou determinável (objeto da intuição), mas não há uma dupla personalidade: o eu puro é propriamente uma pessoa, mas o eu empírico é, da mesma forma que qualquer objeto da intuição, uma coisa. Disso depreende-se que o eu tem a si mesmo como uma pessoa e como uma coisa, mas é impossível explicar como pode o eu ser, ao mesmo tempo, pessoa e objeto. Em outras palavras, não se pode

15. Idem, p. 182 .

16. Idem, p. 183 (grifos nossos).

17. Idem, p. 184. 
explicar como o eu é ao mesmo tempo inteligência, isto é, espontaneidade, e objeto da intuição, isto é, objeto da receptividade.

Entretanto, se o eu empírico é uma coisa (um objeto da intuição), então poderíamos utilizar os conceitos do entendimento (as categorias) e determiná-lo ontologicamente? De acordo com que afirmamos mais acima, o eu empírico não é fundamento ontológico, senão que seu fundamento é um ente: a alma. Podemos determinar o ser deste ente? A aplicação das categorias a este ente constitui-se, segundo o que nos diz Heidegger sobre Kant, num paralogismo da razão pura.

Sob um ponto de vista histórico, a doutrina de Kant dos paralogismos da razão pura é uma crítica da psychologia rationalis, a metafísica tradicional da alma como metafísica dogmática, que, de fato, ele substitui pela metafísica dos costumes. É característico da psychologia rationalis o que, com a ajuda de conceitos puramente ontológicos que aplica ao eu, enquanto "eu penso", trate de obter algum conhecimento sobre este eu como ente, como alma. Nos "Paralogismos da razão pura", Kant mostra que esses argumentos da psicologia metafísica extraídos a partir de conceitos ontológicos e de sua aplicação ao "eu penso" são falácias. ${ }^{18}$

Por que são falácias? Kant, segundo Heidegger, "denomina aos conceitos ontológicos fundamentais categorias. Divide-as em quatro classes: as categorias da quantidade, da qualidade, da relação e da modalidade" ${ }^{19}$ Ao aplicar essas categorias à alma, temos o seguinte: 1) segundo a quantidade: a alma é uma, isto é, sempre a mesma independente das suas mudanças de estado, portanto, permanece de modo absoluto, é, neste sentido, pessoa; 2) com respeito à qualidade: a alma é simples, é incorruptível e não pode ser decomposta em partes; 3) de acordo com a relação: a alma é substância imaterial subsistente no sentido interno, em oposição ao sentido externo que é o corpo. ${ }^{20}$

18. Idem, p. 202.

19. Idem, ibidem.

20. Idem, p. 203. 
Agora, se adicionarmos a categoria da modalidade a essas três primeiras determinações da alma - personalidade, incorruptibilidade e imaterialidade -, que são determinações da espiritualidade, isto é, determinações do "eu penso" (no sentido da psicologia metafísica), perceberemos que, em verdade, não podemos predicá-la espiritualidade. Isso porque a categoria de modalidade é a categoria que determina a alma de uma maneira estrita: como existindo em relação recíproca com um corpo. A alma, nesse sentido, é o fundamento da vida na matéria; ela anima um corpo. Portanto, se a alma existe também em relação recíproca com um corpo, então não podemos dizer que ela é simples, incorruptível e subsistente por si, isto é, que é imortal, mas que sua existência se faz também na relação com o corpo, ou seja, que deixa de ser determinada quando essa relação desaparece. Logo, não podemos obter conhecimento ontológico a partir da aplicação das categorias a este ente (a alma), pois a condição de existência dada pela categoria de modalidade está em contradição em relação às outras.

Resumindo: de um lado, temos a autoconsciência pura, a apercepção transcendental, que revela um sujeito determinante; de outro, temos a autoconsciência empírica, a apreensão, que manifesta um sujeito determinável, um sujeito que não é propriamente sujeito, senão uma coisa que subsiste em meio aos estados empíricos da experiência interna, mas que também se vincula com um objeto do sentido externo: o corpo.

Um conhecimento ontológico sobre cada um dos dois não é possível por motivos distintos: enquanto o sujeito determinante é também pura espontaneidade, isto é, não pode ser determinado na intuição, o sujeito determinável - enquanto objeto da intuição, ou seja, dado na receptividade - é um ente, é somente objeto, que está em relação de reciprocidade com um corpo. Isso tem implicação no conceito de alma que não pode ser imortal (de acordo com as categorias de quantidade, qualidade e relação), pois também tem seu fundamento na matéria (conforme a categoria de modalidade). Não podemos, portanto, aplicar conceitos ontológicos à alma e obter conhecimento ontológico dela como "eu penso", na medida em que o "eu penso" não é o sujeito dado na experiência (determinável), senão que é aquele que, por sua índole, deve tor- 
nar possível a experiência (determinante). Ambos os conceitos de personalidade - a personalidade transcendental e a personalidade psicológica - são conceitos gerais de pessoa. Entretanto, o primeiro é personalidade no sentido formal, pois possui um caráter ontológico, ou seja, o eu, por ser a condição ontológica fundamental, é a unidade que antecede e torna possível a multiplicidade; já o segundo conceito é dependente daquele, na medida em que se manifesta na multiplicidade como um mesmo que subsiste em meio aos estados que modificam continuamente.

Enquanto a autoconsciência por apercepção transcendental é um puro dar-se conta do eu, a apreensão é um ato dirigido ao eu empírico e mediado pela intuição sensível. Agora, há uma autoconsciência que revela o eu num sentido mais central e autêntico. Essa consciência de si não é um dar-se conta de um sujeito determinante (o eu puro), tampouco é um conhecimento teórico do sujeito determinável (o eu empírico). Essa peculiar autoconsciência manifesta a pessoa num sentido mais autêntico e preciso, não como um sujeito determinante ou determinável, senão como um sujeito que determina a si mesmo por meio de uma ação específica: a ação moral. A autoconsciência revela o eu puro prático.

\section{Personalidade moral: o mais estrito e autêntico conceito de pessoa}

Segundo Heidegger:

A personalidade tomada propriamente é a personalidade moral. Se a estrutura formal da personalitas consiste na consciência de si mesmo, então a personalitas moralis deve expressar uma modificaşão da consciência de si mesmo e, portanto, representar uma classe peculiar de autoconsciência. A consciência moral de si mesmo caracteriza apropriadamente a pessoa naquilo que é. ${ }^{21}$

Que modificação da autoconsciência é esta, e o que significa dizer que ela é peculiar? Mais ainda, o que significa dizer que caracteriza a pessoa naquilo que é? Se a autoconsciência moral

21. Idem, p. 186. 
preserva a estrutura da personalidade, isto é, se constitui a partir da efetividade e revela o eu como sendo um mesmo, e, ao mesmo tempo, revela peculiarmente a pessoa naquilo que é, então esta autoconsciência, por sua peculiaridade, deve necessariamente distinguir-se da autoconsciência pura e da autoconsciência empírica.

Se a consciência de si revela "a autêntica espiritualidade [Geinstigkeit] do homem"22, então ela não revela um mesmo eu pela mediação do sentido interno e do sentido externo da intuição sensível, tampouco deve ser um ato reflexivo dirigido às cogitationes, a partir do que aquele que pensa se dá conta de que é um mesmo que está pensando. Segundo Heidegger, "a consciência moral de si mesmo tem de ser um sentimento e deve se distinguir do conhecimento teórico, no sentido teórico do 'eu penso em mim mesmo"'. ${ }^{23}$

De acordo com a visão de Heidegger sobre Kant, na sensibilidade temos o sentimento (num sentido amplo) que se distingue da intuição sensível, a qual é a faculdade de ter sensação. Um sentimento ou é de prazer [Lust] ou é de desprazer [Unlust], e não só é um sentimento por algo, mas também é um sentimento em algo. Em outras palavras, quando temos um sentimento por algo, não somente experimentamos este algo no sentimento, senão que experimentamos a nós mesmos como tendo este sentimento. Dessa forma, o eu se revela como um mesmo de maneira específica ao ter-se a si mesmo diretamente e, portanto, não é mediado pela intuição. Essa é, sob o ponto de vista fenomenológico heideggeriano, a definição universal e formal de sentimento.

Como podemos identificar essa estrutura essencial do sentimento no sentimento moral? O sentimento moral em Kant é o respeito. Há uma diferença fundamental quanto à causalidade do sentimento sensível e o sentimento moral: enquanto o primeiro é causado naturalmente por um sentimento patologicamente produzido, ou seja, é condicionado aos estados corporais, o segundo tem o seu fundamento intelectual, isto é, é causado pela razão. A

22. Idem, p. 187.

23. Idem, p. 188. 
causa do sentimento moral - ou se quisermos, o fundamento de determinação da vontade racional - é a lei moral.

Enquanto produz o sentimento moral, a lei moral tem um duplo efeito: um efeito negativo, a determinação de um sentimento de repúdio a todas as inclinações e, um efeito positivo, a revelação daquilo que efetua e funda a priori esse sentimento.

De acordo com Heidegger, as inclinações, em Kant, ou decorrem do amor próprio ou da presunção. Sobre isso Kant afirma:

A razão prática pura apenas causa dano ao amor-próprio na medida em que ela o limita - enquanto natural e ativo em nós antes da lei moral - apenas à condição da concordância com essa lei, em cujo caso ele denomina-se amor de si racional. Mas ela com certeza abate a presunção, na medida em que todas as exigências de autoestima que precedem a concordância com a lei moral são nulas e totalmente ilegítimas, na medida precisamente em que a certeza de uma disposição que concorda com essa lei é a primeira condição de todo o valor da pessoa [...], e toda a impertinência ante a mesma lei é falsa e contrária à lei. ${ }^{24}$

Não obstante, Heidegger limita-se à investigação do efeito negativo da lei moral com relação à presunção em Kant. O motivo disso vemos em sua argumentação, que nos conduz de imediato à definição de efeito positivo da lei moral. Assim, ao opor-se à resistência subjetiva, debilitando a presunção, a lei moral é objeto de respeito, mas, ao abater a presunção, a lei moral é objeto de sumo respeito, sendo, por conseguinte, um sentimento positivo, o único de que podemos ter conhecimento a priori.

Portanto, respeito, enquanto sentimento, é respeito-por algo (a lei moral a priori) e, ao mesmo tempo, revela um eu que se tem a si mesmo como um agente. Entretanto, segundo Heidegger, a lei moral em Kant não serve para julgar, pois não se manifesta depois de um acontecimento. Ter respeito pela lei não é o motor da lei, senão que faz dessa lei uma máxima subjetiva, ou seja, revela a lei de uma maneira específica. A causalidade intelectual é uma

24. KANT, I. Crítica da razão prática. Ed. bilíngüe. Trad. de Valério Rohden. São Paulo: Martins Fontes, 2003, pp. 254-5. 
causalidade por liberdade, isto é, ao mesmo tempo em que revela a lei, também manifesta o eu puro e livre que, diante da lei, atua ante si mesmo.

Pelo menos uma diferença fundamental pode ser identificada entre esse "eu atuo" da razão pura prática e o "eu atuo" da razão pura: enquanto este último é um puro determinar, o primeiro é um puro determinar-se a si mesmo pela obediência a uma lei a priori prática. Nesse sentido, há uma estrutura intencional no fenômeno do respeito, a saber, o eu submete a si mesmo a uma lei e, simultaneamente, se enaltece. Seguindo a análise heideggeriana de Kant, o enaltecer-se e o submeter-se são análogos aos sentimentos determinados pela sensibilidade: respectivamente, de inclinação e temor, isto é, a tendência para e a tendência a se afastar. Segundo Kant, "não se pode ver-se saciado da majestade dessa lei, e a alma crê elevar-se na mesma medida em que vê a lei santa elevada sobre si e sua frágil natureza". ${ }^{25}$ Essa afirmação pode ser comparada com a seguinte interpretação heideggeriana: "ao submeter-me a mim mesmo à lei, submeto-me a mim mesmo como razão pura; mas isto quer dizer que neste submeter-se a mim mesmo me enalteço a mim mesmo como livre, como um ser que se determina a si mesmo". ${ }^{26}$ Donde podemos concluir que o eu livremente se submete a si mesmo ao ver a sua frágil natureza perante a lei e, ao submeter-se, enaltece a si mesmo, revelando a lei santa para si, ao mesmo tempo em que se manifesta como um sujeito que se determina a si mesmo, fazendo-se patente a si mesmo de maneira mais autêntica, a saber, em sua dignidade.

A autoconsciência moral revela a pessoa em seu sentido mais próprio, apesar de Kant não aprofundar nessa direção, segundo Heidegger. O sentimento moral é, conforme o que nos diz Heidegger, o sentimento de minha existência, e revela o eu como um mesmo de maneira específica, pois é a partir de uma revelação específica da lei moral que o eu manifesta a si mesmo de maneira mais autêntica, isto é, não por meio de um conhecimento teórico,

25. Idem, p. 271.

26. Heidegger, M. Los problemas fundamentales de la fenomenología, p. 192. 
mas como um sentimento de minha existência que manifesta a minha dignidade.

Diz Heidegger: "o respeito é um acesso ôntico a um mesmo do eu, no sentido próprio, que existe facticamente". ${ }^{27}$ Não obstante, se o respeito é o sentimento de minha existência - e se através deste sentimento o eu se revela em sua dignidade, ou seja, enquanto livre, enquanto determinando a si mesmo, e, mais ainda, se é capaz de ter conhecimento a priori da lei moral -, então aqui uma ontologia da existência humana é possível.

Donde podermos distinguir a autoconsciência moral da autoconsciência pura e da autoconsciência empírica, que não permitem um acesso ontológico ao eu por motivos distintos: o eu puro tem caráter ontológico e não pode se manifestar onticamente, assim não é permitido um acesso ao seu ser; por outro lado, o eu empírico tem manifestação ôntica, mas não pode ser revelado ontologicamente, pois a categoria ontológica de modalidade aplicada ao ente não permite que a alma subsista por si mesma, sem um corpo. Todavia, Heidegger afirma o seguinte sobre a autoconsciência moral: "nesta revelação de si mesmo como um ente fático, deve dar-se a possibilidade de determinar a constituição do ente assim manifesto". ${ }^{28}$

Qual seria, então, a constituição ontológica da pessoa que se pode revelar? Heidegger afirma que, em Kant, uma pessoa não deve ser entendida apenas pela concepção ontológica de fim em si mesmo, senão como uma pessoa que existe objetivamente como fim em si mesmo. E, por isso, distingue-se de uma coisa existente dada na sensibilidade, que é um meio.

O homem existe como um fim em si mesmo; não é nunca um meio, nem sequer um meio para Deus, senão que também ante Deus, ele é seu próprio fim. A partir daqui, isto é, a partir da caracterização ontológica do ente que não é só concebido por outros como um fim e tomado como tal, senão que existe objetivamente - efetivamente - como um fim, põe-se em claro o autêntico sentido ontológico

27. Idem, p. 177.

28. Idem, p. 194. 
da pessoa moral. A pessoa moral existe como seu próprio fim; ela mesma é um fim. ${ }^{29}$

A humanidade (no sentido de quidditas, de índole essencial e não o de gênero humano) do homem, isto é, o seu autêntico dever ser, somente é revelado com a autoconsciência moral. Conforme a interpretação de Heidegger, uma pessoa, enquanto existe efetivamente como um fim, encontra-se no reino dos fins, que não é nenhum sistema de valores hierarquizados, senão o reino de convivência das pessoas existentes.

Em suma, a autoconsciência moral nos manifesta a pessoa no sentido mais estrito porque não é, como na apercepção transcendental, em que o sujeito se revela como um mesmo que subjaz em cada uma de suas cogitaciones. Tampouco é um sujeito apreendido como um mesmo que subsiste em meio aos seus estados empíricos internos que se modificam continuamente. A pessoa, no sentido mais estrito, se revela a partir de uma única lei moral a priori, que é revelada no sentimento moral (respeito) e que é objeto deste. No sentimento moral a pessoa também tem-se a si mesma, não como um objeto, tampouco como um sujeito simplesmente puro, mas como possuindo uma dignidade. Esse "ter-se a si mesmo" enquanto dignidade, é o que nos dá o sentido mais autêntico de pessoa.

Portanto, com a definição mais estrita e autêntica de pessoa, não somente nos conduzimos a seu sentido mais próprio, senão também à possibilidade de uma ontologia. A partir do sentimento moral, o eu tem acesso ôntico a si mesmo, o que viabiliza uma constituição ontológica de sua existência.

Embora Kant se mova dentro dos limites pré-traçados pela ontologia tradicional do subsistente, a análise do respeito e da pessoa moral, segundo Heidegger, "não passa de ser um intento, mesmo que imensamente importante, de sacudir-se inconscientemente o peso da ontologia tradicional" ${ }^{30}$ A interpretação de Heidegger sobre a definição ontológica da pessoa como um fim embora Kant não tenha levado a cabo a investigação da índole es-

29. Idem, p. 195.

30. Idem, p. 209. 
sencial de um fim, bem como a sua possibilidade ontológica - tem ressonância na definição de Dasein. Assim, o ser do ente na pessoa moral em Kant, da mesma forma que no Dasein, não se limita tão-somente em ser, mas sim, leva em sua própria existência o seu poder ser. Não obstante, a relação, sob o ponto de vista estrutural ontológico, entre a pessoa moral em Kant, segundo Heidegger, e a definição de Dasein pode ser tema de um outro trabalho.

\section{Bibliografia}

HEIDEGGER, M. Los problemas fundamentales de la fenomenología. Trad. de Juan José Garcia Norro. Madri: Editorial Trotta, 2000.

KANT, I. Crítica da razão prática. Ed. bilíngüe. Trad. de Valério Rohden. São Paulo: Martins Fontes, 2003. 